\title{
Transients Induced on Control Cables and Secondary Circuit of Instrument Transformers in a GIS During Switching Operations
}

\author{
M. Mohana Rao, M. Joy Thomas, and B. P. Singh
}

\begin{abstract}
The transient fields generated during switching operations in gas-insulated substations (GIS) can have rise times in the order of a few nanoseconds. Transient fields, which are developed internally to the gas-insulated modules, leak into the external environment through discontinuities and interfere with nearby electronics. Depending on the configuration of the GIS and the observation point, amplitudes of the electric and magnetic fields could be of the order of a few tens of kilovolts per meter and a few hundreds of amps per meter, respectively. These transient fields, in turn, induce voltages in the control cables and secondary circuit of the instrument transformers, which result in malfunctioning of the primary equipment. In this paper, induced transient voltages in the control circuitry and their frequency spectra have been calculated due to the transient fields, leaking out from the gas-to-air bushing and the gas-insulated bus section of a $245-\mathrm{kV}$-rated GIS, during switching operations. The effect of the length of control circuit, type of grounding of the cable sheath (both-end/one-end), characteristics of the transient fields, type of secondary circuit (i.e., current transformer/potential transformer) and LC loading of the control circuitry on the induced voltages have been analyzed and reported.
\end{abstract}

Index Terms-Control circuitry, gas-insulated substation (GIS), switching, transient currents, transient fields, transient voltages.

\section{INTRODUCTION}

I $\mathrm{N}$ a gas-insulated substation (GIS), very fast transient overvoltages (VFTOs) are generated mainly due to switching operations [1]. These transient voltages are associated with very fast transient currents (VFTCs) of about a few kiloamps, depending on the location of the switch operated, the substation layout, rated voltage of the substation, distance of the observation point from the switch, etc. [2]. The transient voltages/currents radiate electromagnetic (EM) fields during their propagation along the high-tension (HT) conductor of the gas-insulated equipment as the associated frequencies are in the order of tens of megahertz. These transient fields, in turn, leak into the external environment of the GIS through discontinuities such as $\mathrm{SF}_{6}$ gas-to-air bushing, gas-to-cable termination, nonmetallic flanges, nonmetallic viewing ports, etc., and may interact with the nearby control circuitry.

Manuscript received September 29, 2005; revised July 13, 2006. Paper no. TPWRD-00588-2005.

M. M. Rao and B. P. Singh are with Bharat Heavy Electricals Ltd., Corporate R\&D, Hyderabad 500 093, India (e-mail: mmrao@bhelrnd.co.in; bpsingh@bhelrnd.co.in).

M. J. Thomas is with the Department of High Voltage Engineering, Indian Institute of Science, Bangalore 560 012, India (e-mail: thoma@hve.iisc.ernet. in).

Digital Object Identifier 10.1109/TPWRD.2007.901292
Even though the transient field amplitudes, in general, decrease with an increase of distance from the high-voltage (HV) bus, it is very often seen that the electronic equipment are present in the vicinity of the HV equipment of the GIS. This has lead to concern for the compatibility of the electronic equipment with the interfering environment, in which they must operate satisfactorily. Each switching operation produces multiple transient fields, whose magnitude, number, and waveshape vary with the rated voltage of the substation, type/speed of the switch being operated, and electrical characteristics of the high-voltage bus. These electromagnetic (EM) fields contribute to significant radiated fields and couple energy to the control equipment [3].

The transient fields generated during switching operations induce currents on the metallic sheath of the cable. These transient currents, in turn, develop voltages on the central conductor of the cable via transfer impedance and by a mechanism of the pigtail coupling [4]. Transfer impedance is a characteristic parameter of the control cable and the shielded cables have lower transfer impedance. Pigtail coupling is the inductive coupling between the metallic sheath termination (pigtail) and the load circuit of the cable. The induced voltages at the control cable terminals appear across the relays, integrated circuits (ICs), sensors, etc., of the secondary circuit and result in malfunctioning of the primary equipment. Alternatively, the transient fields may interact with the control wiring connected between the primary and secondary equipment, which result in transient voltages in the control circuitry of the GIS [3]-[5].

In this study, induced voltages have been calculated on the control cables with both-end/one-end grounding of the cable sheath. In the first phase of the study, induced voltages have been calculated in the control circuitry for the entire frequency range, by assuming fixed transient field levels. This exercise will be helpful to understand the effect of frequency content of the transient fields on the induced voltages in the control circuitry. The influence of type of the control circuit and LC loading of the same on the voltage levels have been analyzed. Finally, the induced voltages are calculated at the load circuit of the control cables/wiring due to the transient field emission from the GIS modules. The dominant frequency components of these voltages have also been reported.

\section{TRANSIENT FIELDS IN A 245-kV GIS}

The transient field emission levels from the gas-insulated bus section through the nonmetallic flange of the support insulator and from the gas-to-air bushing through the composite insulator housing, in a $245-\mathrm{kV}$ GIS, have been quantified for very fast 


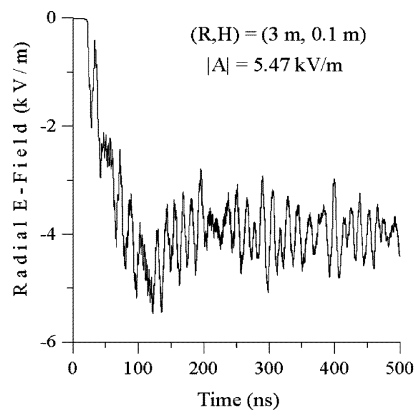

(a)
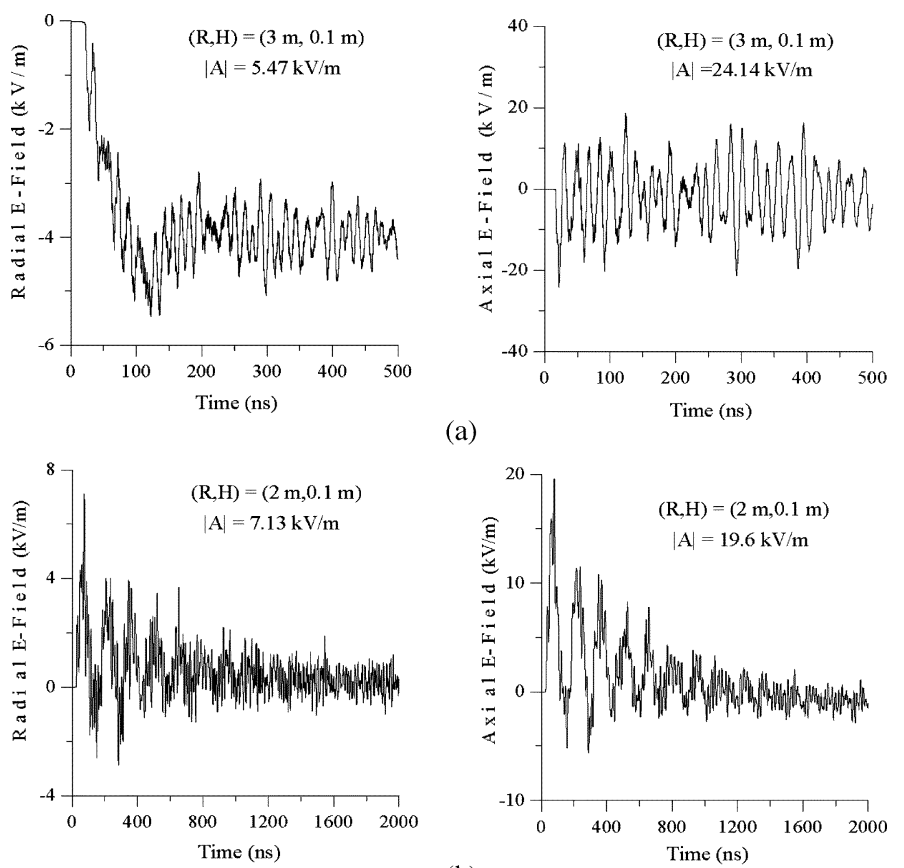

(b)

Fig. 1. Transient fields generated during switching. (a) Bus section. (b) Gas-to-air brushing.

transient currents generated during switching events [6]. For the calculation of these currents, a $245-\mathrm{kV}$ GIS of segregated phase configuration is considered. The nonmetallic flange need not necessarily be a part of the support insulator, but also could be an insulated flange of the current transformer or the gas-to-cable termination. To calculate the emission levels from the bus section, the transient current waveform at the disconnector switch (DS) during its operation has been considered as an excitation to the bus section model. Similarly, for the computation of the emission levels from the gas-to-air bushing, the transient current waveform obtained at the GIS-bushing junction [2], during a switching operation in the $245-\mathrm{kV}$ GIS, is considered as excitation to the bushing model. For the estimation of emission levels, a numerical model using a modified finite-difference time-domain (FDTD) technique, was developed for the 245-kV-rated gas-insulated bus section and the gas-to-air bushing [6]. In GIS, the time-varying E-field waveforms are found to be oscillatory unlike in conventional substations [7].

Fig. 1 shows the transient fields leaking out from the gasinsulated bus duct and the gas-to-air bushing modules during switching operations. From the figure, it is seen that the radial and axial E-field levels computed for the bus section model, at a radial distance $(\mathrm{R})$ of $3 \mathrm{~m}$, axially located at the middle of the bus section and just above the ground plane $(\sigma=0.01 \mathrm{mho} / \mathrm{m})$ are 5.47 and $24.14 \mathrm{kV} / \mathrm{m}$, respectively. It is important to note that the transient field levels change in the axial direction also. The highest radial and axial E-field levels computed for the bus section model at a radial distance of $3 \mathrm{~m}$ are 22.5 and $27.6 \mathrm{kV} / \mathrm{m}$, respectively. These field levels are obtained at an axial distance of $0.5 \mathrm{~m}$ from the middle of the bus section. Similarly, the radial and axial E-fields leaking out from the bushing at a radial distance of $2 \mathrm{~m}$ and just above the ground plane $(\mathrm{H})$ are 7.13 and $19.6 \mathrm{kV} / \mathrm{m}$, respectively. The field levels, computed with a metallic structure on the ground plane, are found to have significant enhancement, which are 22 and $53.4 \mathrm{kV} / \mathrm{m}$, respectively [7]. The average E-field enhancement factor is about 2 to 4 , depending on the observation point and the frequency content of the transient fields.

\section{INDUCED TRANSIENTS ON CONTROL CABLES}

Fig. 2 shows the control cable used for the present study. The induced current is calculated, by assuming the control cable/ sheath as a distributed transmission line. The transients in the control cables can be quantified in terms of the radial E-field along the terminations and axial E-field along the sheath. The solution is obtained by integrating the responses due to infinitesimal voltage sources produced by the transient fields along the terminations and the sheath. The following equation is being evaluated based on the above voltage sources [8]:

$$
\begin{aligned}
\mathrm{I}(\mathrm{x}, \omega)= & \frac{\mathrm{Z}_{0} \cos \beta(\mathrm{L}-\mathrm{x})+\mathrm{j} \mathrm{Z}_{2} \sin \beta(\mathrm{L}-\mathrm{x})}{\mathrm{Z}_{0} \mathrm{D}} \\
& * \mathrm{k} \int_{0}^{\mathrm{x}} \mathrm{E}_{\mathrm{z}}(\mathrm{z}, \omega)\left[\mathrm{Z}_{0} \cos \beta \mathrm{z}+\mathrm{j} \mathrm{Z}_{1} \sin \beta \mathrm{z}\right] \mathrm{dz} \\
& +\frac{\mathrm{Z}_{0} \cos \beta \mathrm{x}+\mathrm{j} \mathrm{Z}_{1} \sin \beta \mathrm{x}}{\mathrm{Z}_{0} \mathrm{D}} \\
& * \mathrm{k} \int_{\mathrm{x}}^{\mathrm{L}} \mathrm{E}_{\mathrm{z}}(\mathrm{z}, \omega)\left[\mathrm{Z}_{0} \cos \beta(\mathrm{L}-\mathrm{z})+\mathrm{j} \mathrm{Z}_{2} \sin \beta(\mathrm{L}-\mathrm{z})\right] \mathrm{dz} \\
& +\frac{\mathrm{k}}{\mathrm{D}}\left[\mathrm{Z}_{0} \cos \beta(\mathrm{L}-\mathrm{x})+\mathrm{j} \mathrm{Z}_{2} \sin \beta(\mathrm{L}-\mathrm{x})\right] \\
& * \int_{0}^{\mathrm{d}} \mathrm{E}_{\mathrm{r}}(\mathrm{r}, 0, \omega) \mathrm{dr}-\frac{\mathrm{k}}{\mathrm{D}}\left[\mathrm{Z}_{0} \cos \beta \mathrm{x}+\mathrm{j} \mathrm{Z}_{1} \sin \beta \mathrm{x}\right] \\
& * \int_{0}^{\mathrm{d}} \mathrm{E}_{\mathrm{r}}(\mathrm{r}, \mathrm{L}, \omega) \mathrm{dr} .
\end{aligned}
$$

The multiplication factor $\mathrm{k}=2$ is considered to represent the image of the cable sheath. Induced current obtained from (1) is a function of $x$ and $\omega$. The induced voltages are calculated on the central conductor of cable using the following equation:

$$
\mathrm{dV}(\mathrm{x}, \omega)=\mathrm{Z}_{\mathrm{t}}(\omega) * \mathrm{I}(\mathrm{x}, \omega) \mathrm{dx}
$$

where

$$
\begin{aligned}
& \text { D } \quad\left(\mathrm{Z}_{0} \mathrm{Z}_{1}+\mathrm{Z}_{0} \mathrm{Z}_{2}\right) \cos \beta \mathrm{L}+\mathrm{j}\left(\mathrm{Z}_{0}^{2}+\mathrm{Z}_{1} \mathrm{Z}_{2}\right) \sin \beta \mathrm{L} \\
& \mathrm{Z}_{\mathrm{a}}, \mathrm{Z}_{\mathrm{b}} \quad \text { terminal impedance of the cable; } \\
& \mathrm{Z}_{\mathrm{c}} \quad \text { characteristic impedance of the cable; } \\
& \mathrm{Z}_{1} / 2, \mathrm{Z}_{2} / 2 \text { terminal impedance of the cable sheath; } \\
& \mathrm{Z}_{0} \quad \text { characteristic impedance of the cable sheath; } \\
& \beta \quad 2 \pi / \lambda, \lambda \text { is wavelength (cable sheath); } \\
& \beta_{1} \quad 2 \pi / \lambda_{1}, \lambda_{1} \text { is wavelength (cable); } \\
& \mathrm{L} \quad \text { length of the cable; } \\
& \mathrm{d} / 2 \quad \text { height of the cable sheath above ground (h); } \\
& \text { aa diameter of the cable sheath; } \\
& \mathrm{Z}_{\mathrm{t}} \quad \text { transfer impedance of the control cable; } \\
& \mathrm{E}_{\mathrm{z}} \text { and } \mathrm{E}_{\mathrm{r}} \quad \text { axial and radial electric field; } \\
& \mathrm{X}, \mathrm{Z} \quad \text { axial distance from the cable terminal. }
\end{aligned}
$$




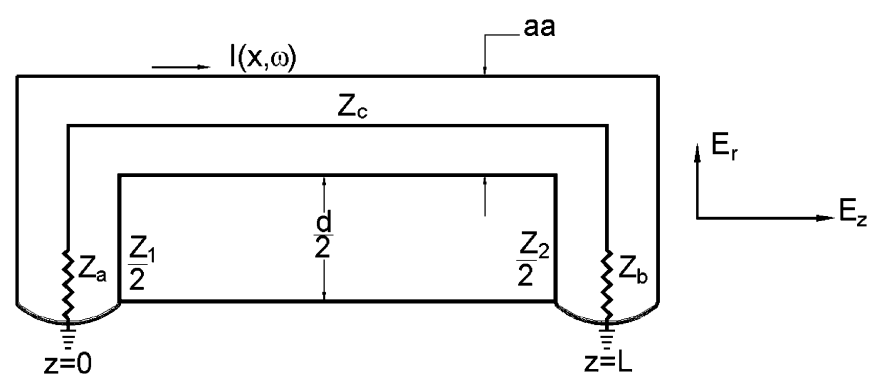

Fig. 2. Configuration of the control cable.

The product of the transfer impedance and the induced current on the cable sheath, integrated over the length of the cable, produces induced voltage on the central conductor of the cable. The assumption of the constant field levels all along the cable may not be valid for longer lengths. Hence, attenuation of the transient field levels with distance has been considered to understand its effect on the induced voltage levels in the control circuitry of the substation. The transient field levels are found to be attenuating with distance at the rate of $\mathrm{E} \propto$ distance $^{-1.5}[9]$. This attenuation factor is more appropriate in the GIS. Here, the cable/wiring is considered to be located at different distances from the transient electromagnetic-interference (EMI) source.

A control cable with the following specifications is being considered for the study [4].

1) Length of the cable varies between $1 \mathrm{~m}$ and $5 \mathrm{~m}$.

2) Surge impedance of the sheath $\left(Z_{0}\right)=410.7$ and $879.6 \Omega$.

3) Surge impedance of the cable $=50 \Omega$.

4) Height of the cable sheath above ground $=0.02 \mathrm{~m}$ and $1.0 \mathrm{~m}$.

5) Transfer impedance of the cable $=3.5 \mathrm{~m} \Omega+\mathrm{j} \omega *$ $4.8 \mathrm{nH} / \mathrm{m}$.

6) Cable sheath grounding resistance $=1 \Omega$.

7) Load resistance of the control cable $=50 \Omega$.

The transient currents and voltages are expressed in $\mathrm{dB} \mu \mathrm{A}$ and $\mathrm{dBmV}$, respectively. The parameter $\mathrm{dB} \mu \mathrm{A}$ is defined as $20 \mathrm{Log}$ $(\mathrm{I} / \mu \mathrm{A})$ and $\mathrm{dBmV}$ is defined as $20 \log (\mathrm{V} / \mathrm{mV})$. Here, $\mathrm{I}$ and $\mathrm{V}$ are the induced transient current and voltage, respectively.

\section{A. Induced Currents in the Control Cable Sheath}

The substation environment, in general, illuminates with both axial and radial E-fields during a switching event. In the initial phase of the study, the radial and axial E-field levels are assumed to each be $10 \mathrm{kV} / \mathrm{m}$ and are constant for the entire frequency range of the transient fields (i.e., 1 to $300 \mathrm{MHz}$ ). The transient current magnitude due to the axial E-fields decreases with an increase in frequency for both-end grounding of the cable sheath and increases with an increase of frequency for one-end grounding of the cable sheath (see Table I). Interestingly, there is a crossover frequency below which both-end grounding of the cable sheath gives higher transient currents and above which one-end grounding of the cable sheath gives higher currents. For a $1 \mathrm{~m}$ length of the cable, this frequency is found to be around $50 \mathrm{MHz}$. Depending on the length of the cable, there is a resonant frequency, beyond which the inductive reactance dominates the capacitive reactance of the cable sheath. Thus,
TABLE I

Highest Induced CuRrent in CABLE Sheath Due to Transient FieldS

\begin{tabular}{|c|c|c|c|c|c|c|}
\hline \multirow{2}{*}{$\begin{array}{c}\mathrm{f} \\
(\mathrm{MHz})\end{array}$} & \multicolumn{6}{|c|}{ Induced Current $(\mathrm{dB} \mu \mathrm{A}), \mathrm{h}=0.02 \mathrm{~m}$} \\
\cline { 2 - 7 } & \multicolumn{2}{|c|}{ Axial Field $\left(\mathrm{E}_{\mathrm{z}}\right)$} & \multicolumn{2}{|c|}{ Radial Field $\left(\mathrm{E}_{\mathrm{r}}\right)$} & \multicolumn{2}{c|}{ Combined Fields } \\
\cline { 2 - 7 } & $\begin{array}{c}\text { Both- } \\
\text { end }\end{array}$ & $\begin{array}{c}\text { One- } \\
\text { end }\end{array}$ & $\begin{array}{c}\text { Both- } \\
\text { end }\end{array}$ & $\begin{array}{c}\text { One- } \\
\text { end }\end{array}$ & $\begin{array}{c}\text { Both- } \\
\text { end }\end{array}$ & $\begin{array}{c}\text { One- } \\
\text { end }\end{array}$ \\
\hline 1 & 186.6 & 114.0 & 86.1 & 92.1 & 186.6 & 113.3 \\
\hline 5 & 173.4 & 128.1 & 100.1 & 106.1 & 173.4 & 127.3 \\
\hline 10 & 167.4 & 134.2 & 106.1 & 112.2 & 167.4 & 133.5 \\
\hline 50 & 153.5 & 153.0 & 120.9 & 130.3 & 153.7 & 152.4 \\
\hline 100 & 147.5 & 157.3 & 130.3 & 132.3 & 148.6 & 156.9 \\
\hline 200 & 141.4 & 150.4 & 132.3 & 131.0 & 144.0 & 151.2 \\
\hline 300 & 138.1 & 144.0 & 125.8 & 125.8 & 139.8 & 144.2 \\
\hline
\end{tabular}

beyond this frequency, current magnitude decreases with an increase of frequency of the transient fields, irrespective of the type of grounding of the sheath. For the radial E-fields, the induced current increases with an increase of the frequency. This is true up to the resonant frequency, for both types of grounding of the sheath. For both-end grounding of the sheath, the incident current contributed by the voltage sources along the grounded terminations (at either end of the sheath) cancel out each other and result in a lower current level compared to the one-end grounding of the sheath. This cancellation effect further leads to an increase in the current magnitude with an increase of frequency. The induced currents due to radial E-fields are found to be less than that due to the axial E-fields for 0.02-m height of the cable sheath above the ground. Fig. 3 shows the transient current in a control cable sheath due to the combined fields (i.e., both axial and radial fields). Beyond the resonant frequency, the transient current produces a standing wave pattern along the length of the cable. From this figure along with Table I, it is evident that the induced current on the sheath due to combined fields is observed to be almost the same as that due to the axial E-fields, for 0.02-m height of the sheath above the ground. Interestingly, with an increase in height of the cable above the ground, there is a specific frequency, beyond which, the induced current contributed by the radial E-fields is more compared to that of the axial E-fields. More clearly, at smaller heights of the cable above the ground, the axial E-field level dictates the current magnitude for the entire frequency range of transient fields. With increasing height of the cable, current magnitude due to radial E-fields becomes significant. This may be due to the fact that the incident voltage/current caused by radial E-field increases with an increase of height of the cable. For one-end grounding of the sheath below the crossover frequency, induced current increases with an increase of length of the cable. This may be due to a significant increase in the induced current contributed by the axial E-field.

\section{B. Induced Voltages in the Control Cable Circuitry}

The transient currents induced on the metallic sheath of the control cable, in turn, develop voltages on the central conductor of the cable depending on its transfer impedance. Interestingly, there is a crossover frequency for the cable, below which the induced voltage for one-end grounding is lower than that for the both-end grounding of the cable sheath [shown in Fig. 4(a)]. This frequency level decreases with an increase of height of the cable above the ground and one-end grounding of the cable 


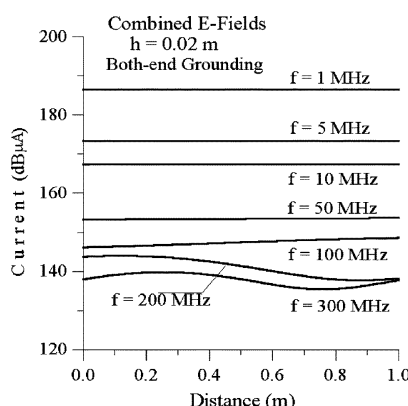

(a)

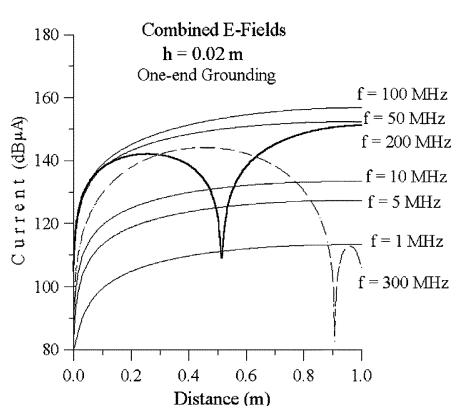

(b)
Fig. 3. Induced currents on the cable sheath due to the combined E-fields. (a). Both-end grounding. (b). One-end grounding.

sheath tends to become ineffective for the GIS application. The resonant frequencies of the cable are observed to be a function of the type of the grounding of the sheath, length of the cable, and the electrical characteristics of the cable/cable sheath. Further, the induced voltage levels at these frequencies depend on the attenuation loss offered by the cable sheath and the attenuation of the transient fields with distance. The poles in the transient current waveform (or resonant frequencies) occur at multiples of $150 / \mathrm{L} \mathrm{MHz}$ ( $\mathrm{L}$ is length of the cable in meters). Induced voltage levels at these frequencies are reduced considerably due to a small mismatch of the control cable terminal impedance. In order to understand the effect of length of the cable on the resonant frequencies as well as the induced voltage levels, a calculation has been made for a 5-m length of the cable. Fig. 4(b) shows the voltage waveform for both types of grounding of the sheath. With an increase of the length of the cable, the crossover frequency level decreases and the number of resonant frequencies increases. At lower resonant frequencies, the induced voltage for both-end grounding of the cable sheath is at considerable level, even though the transfer impedance is low. This may be because of the higher induced current on the cable sheath. At higher resonant frequencies (i.e., beyond $100 \mathrm{MHz}$ ), the induced voltages are high for both types of grounding, due to higher transfer impedance of the cable along with the marginal current levels. For attenuating fields, both-end grounding of the cable sheath gives slightly higher transient voltages at some of the resonant frequencies. This may be due to nonuniform voltage distribution along the sheath. From the analysis, it is also clear that the reduction in induced voltage levels due to the attenuating fields is of the order of 10 to $20 \mathrm{dBmV}$, depending on the type of grounding of the cable sheath.

\section{Transient Voltages in Cable Circuitry of a 245-kV GIS}

Based on the induced voltages obtained from different configurations of the control cable for the fixed transient field levels, it has been proposed to calculate the transient voltages due to the transient field emission from the 245-kV GIS [see Fig. 1(a)]. For the calculation of induced voltages, the time-varying E-field waveforms (both radial and axial) have been transferred into the frequency scale, which consist of both real and imaginary parts. The response of the control cable sheath has been calculated for these input data at each frequency step. To calculate the time-varying voltage waveform, the frequency spectrum of the
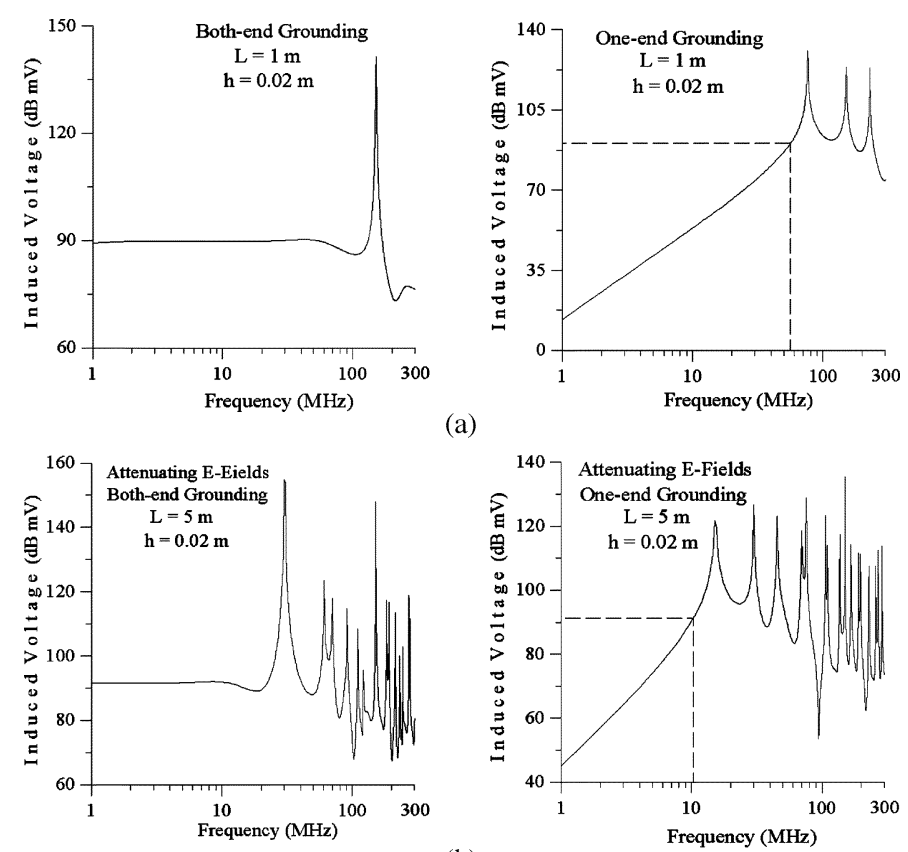

(a)

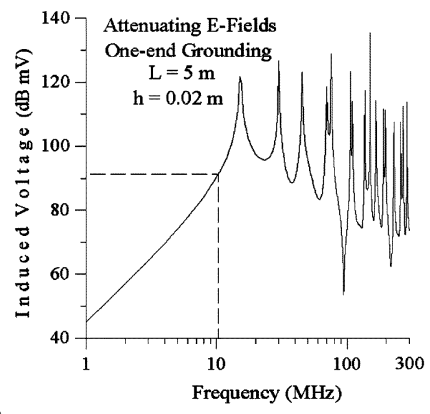

(b)

Fig. 4. Induced voltages at the load circuit of the control cable for both-end and one-end grounding of the cable sheath. (a). $\mathrm{L}=1 \mathrm{~m}$. (b). $\mathrm{L}=5 \mathrm{~m}$.

transient voltage has been converted back into the time scale, using the inverse fast Fourier transform (IFFT) technique. The transient voltages have been calculated for both types of the cable sheath grounding and it has been observed that the transient voltages at the cable terminals are in the range of few tens of volts to a few hundreds of volts (Fig. 5). In order to understand the frequency content of the transient voltages, frequency spectra are calculated for the voltages obtained from different control circuits (see Fig. 6). From Figs. 5 and 6, it is seen that one-end grounding of the cable sheath gives higher transient voltages than both-end grounding of the sheath and the effect is high for longer lengths of the cable. This may be due to: 1) one-end grounding of the sheath results in higher voltages than both-end grounding, beyond crossover frequency and 2) a decrease in crossover frequency of the cable with an increase of the length of the cable. More clearly, for longer lengths of the cable with one-end grounding of the sheath, induced voltage waveform is associated with the frequency content of the order of a few megahertz also. At the same time, for both-end grounding of the sheath, the highest current magnitude is more or less the same with an increase of the length of the cable. However, the current variation along the sheath becomes oscillatory beyond the resonant frequency and, hence, results in only a marginal increase in the voltage levels.

\section{InduCED TRANSIENT VOLTAGES IN THE SECONDARY CIRCUIT OF INSTRUMENT TRANSFORMERS}

In an electrical substation, instrument transformers [i.e., current transformers (CT) and potential transformers (PT)] are used to measure the system current and voltage, respectively. These transformers are also used for the protection of the substation equipments. Thus, the secondary terminals of these transformers are connected to the control circuitry of the GIS. 

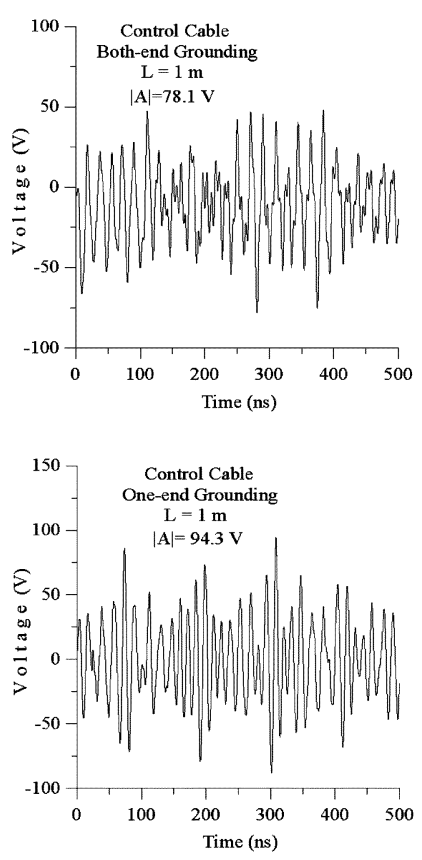

(a)
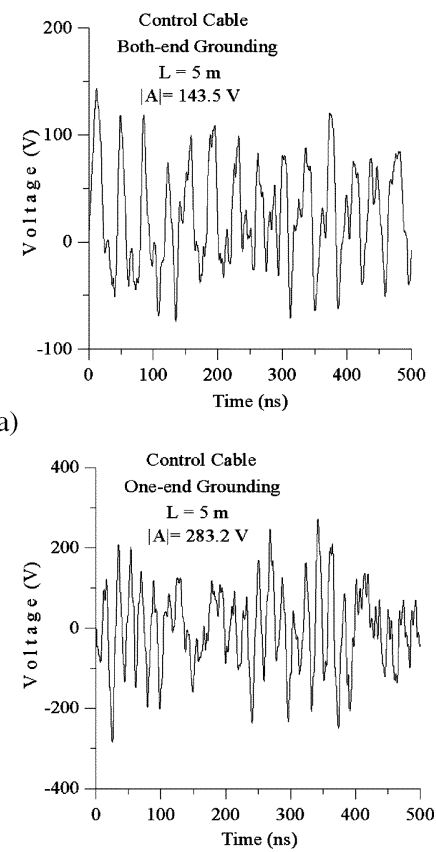

(b)

Fig. 5. Induced transient voltages at the load circuit of the control cable. (a). Both-end grounding (b). One-end grounding.
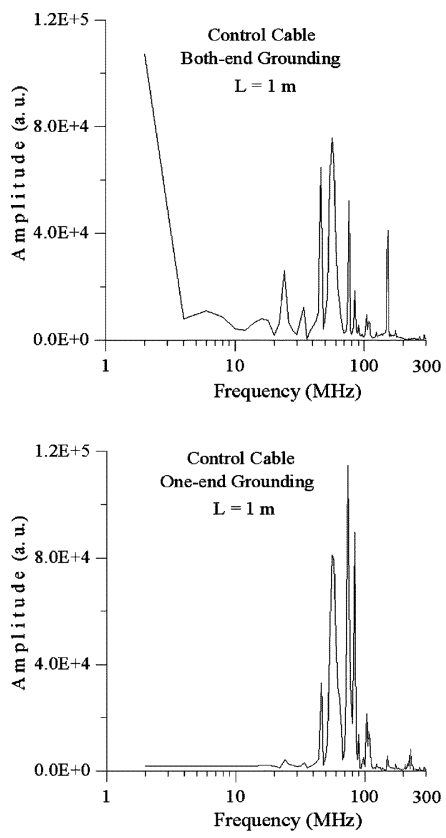

(a)
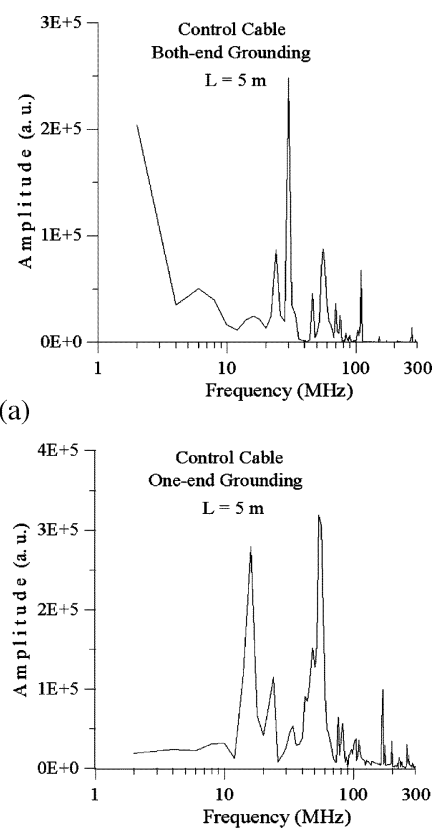

(b)

Fig. 6. Frequency spectra of the transient voltages at the load circuit of the control cable. (a) Both-end grounding. (b) One-end grounding.

The transient fields induce voltages in the control wiring, connected between the instrument transformers and the electronic equipment, such as relays, the data-acquisition system, processors, ICs, etc. This may result in significant voltages at the load circuit of the control wiring, depending on the frequency response of the above equipment. In the present study, the CT and PT wiring with various source/load conditions have been considered to simulate induced voltages in the control circuitry present within the GIS. Fig. 7 shows the control wiring used in

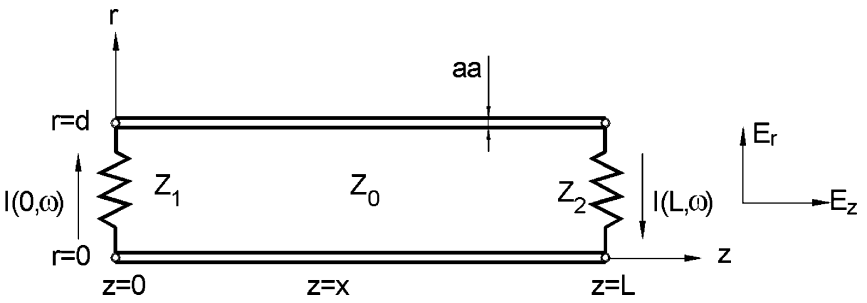

Fig. 7. Configuration of the instrument transformers control wiring.

the study. To calculate induced voltages, (1) has been modified by changing the multiplication factor, $\mathrm{k}$ as 1 for the control wiring configuration versus 2 for the control cable configuration. Terminal impedance of the control circuitry changes with the application of the wiring (i.e., for the CT or for the PT). Control wiring with the following specifications is considered for the study.

1) Length of the wiring (L) varies between $1 \mathrm{~m}$ and $5 \mathrm{~m}$.

2) Area of single core wire is $2.5 \mathrm{~mm}^{2}$.

3) Surge impedance $\left(Z_{0}\right)$ of the wiring is $469 \Omega$.

4) Distance between wiring (d) above the ground is $0.04 \mathrm{~m}$.

The source and the load resistance of the control wiring for the CT secondary circuit are considered to be $10 \Omega$ and $1 \Omega$, respectively. Thus, the CT control circuit is closer to both-end grounding of the wiring. In the first phase of the study on the control wiring, the radial and axial E-fields are considered to be $10 \mathrm{kV} / \mathrm{m}$ for the entire frequency range. Fig. 8 (a) shows the transient voltage at load terminals for $1-\mathrm{m}$ length of the circuit. From this figure, it is seen that the induced voltage decreases with an increase of the frequency except at a resonant frequency of about $152 \mathrm{MHz}$ (depending on the length of the wiring). This may be due to the fact that the current magnitude decreases with an increase of frequency. Even though the phenomenon is more or less the same with increased length of the wiring, induced voltages are found to be rich with a greater number of resonant frequencies [see Fig. 8(b)]. Interestingly, there is a considerable change in the transient voltage level because of the presence of stray inductance $(1 \mu \mathrm{H})$ in series with the source/load resistance and stray capacitance $(10 \mathrm{pF})$ across their terminals. Due to the inductive and capacitive (LC) loading, the induced voltages increase with an increase of the frequency and the amplitudes at resonant frequencies increase significantly [see Fig. 8(c)]. Induced voltage levels at a few megahertz also change considerably due to the presence of the above inductance. This may result in a both-end open system for a certain frequency band of the transient fields. At very high frequencies, the stray capacitance offers a low impedance path and the control circuit again becomes close to the both-end grounding system. Further, the reduction in voltage levels due to the attenuating fields is in the order of 10 to $12 \mathrm{dBmV}$, depending on the frequency content of the transient fields [see Fig. 8(d)].

The source and the load resistance of the control wiring for the PT secondary circuit are considered to be $1.5 \Omega$ and $10^{3} \Omega$, respectively. Thus, the potential transformer control circuit is closer to the one-end grounding of the wiring. Fig. 9(a) shows the induced voltage at the load terminals for 1-m length of the 


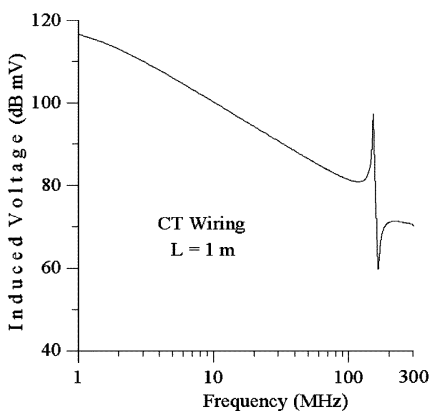

(a)

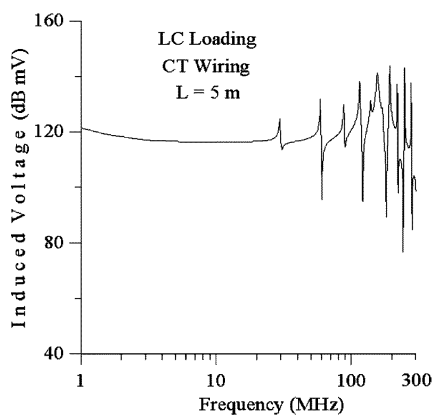

(c)

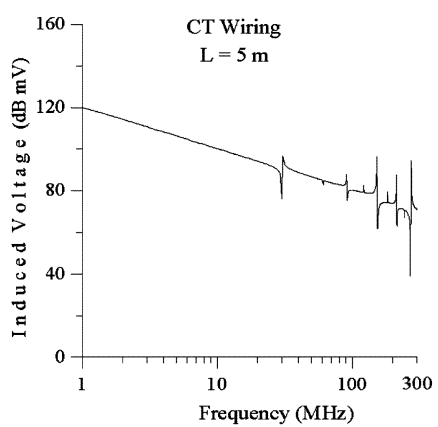

(b)

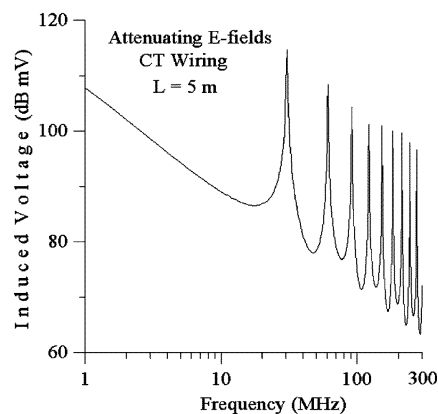

(d)

Fig. 8. Induced voltages at the load circuit of the CT control wiring.

wiring. From this figure, it is seen that the induced voltage experienced by the load circuit is constant up to a few tens of megahertz and beyond that, the voltage level decreases with an increase of frequency. At the same time, there is a possibility of resonant frequencies of 76 and $228 \mathrm{MHz}$. With increased length of the wiring, the phenomenon is more or less the same except that the greater number of critical frequencies are present [see Fig. 9(b)]. For the PT circuit, it is seen that the transient voltage level increases with an increase of the load resistance. As a matter of fact, the load impedance of the PT secondary circuit is highly dependent on the connected electronic equipment. Moreover, depending on the requirements (i.e., either for metering or protection or control), the load resistance could be as high as $10^{6} \Omega$. Interestingly, the induced voltage may not change significantly at low frequencies (say, less than a few megahertz) due to the presence of stray inductance in series with the source/load resistance of the control wiring [see Fig. 9(c)]. However, there is a considerable change in the voltage levels for high-frequency transient fields due to the LC loading at the high-resistance termination of the PT control circuit. Further, the reduction in induced voltage levels due to attenuating E-fields is of the order of $20 \mathrm{dBmV}$, depending on frequency of the transient fields [see Fig. 9(d)].

\section{A. Transient Voltages in the Control Wiring Circuitry of the 245-kV GIS}

Fig. 10 shows the transient voltages induced in the secondary circuit of the instrument transformers due to the transient field emission from the bus section [see Fig. 1(a)]. From the study, the following results are obtained.

1) Transient voltages in the secondary circuit are more for the potential transformers than for the current transformers

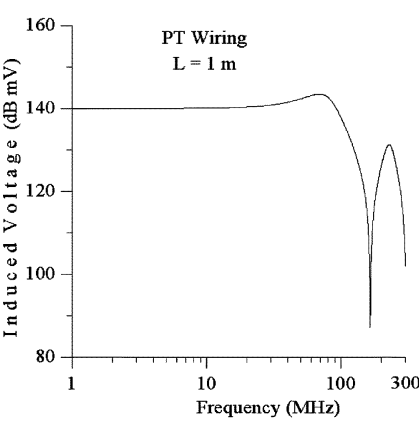

(a)

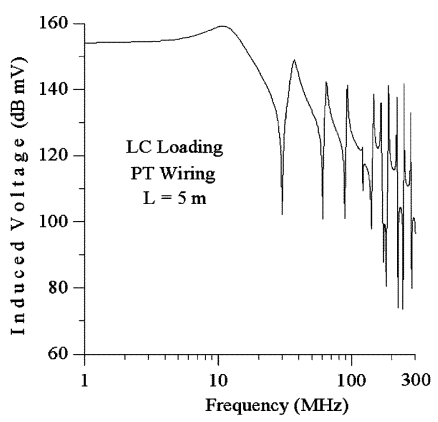

(c)

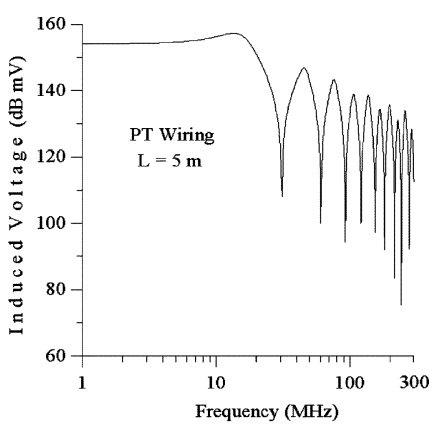

(b)

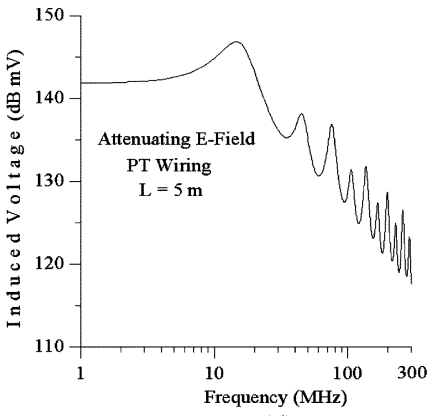

(d)
Fig. 9. Induced voltages at the load circuit of the PT control wiring.

[see Fig. 10(a) and (b)]. This may be due to the high-resistance termination of the PT control circuit.

2) Induced voltages appearing at the CT secondary circuit increase due to LC loading. The inductive reactance of terminal impedance results in the both-end open condition to the CT control circuit for a certain frequency band and experiences higher transient voltages [see Fig. 10(a) and (c)].

3) The transient voltage level in the PT secondary circuit decreases with LC loading [see Fig. 10(b) and (d)]. This may be due to: 1) high terminal resistance of the system and 2) capacitance of LC loading offers a low-impedance path for the induced transients, whose frequency components are in the order of a few tens of megahertz.

4) The reduction in the induced voltages, due to the attenuating E-fields, is more for the PT control circuit than for the CT control circuit [see Fig. 10(c)-(f)]. This may be due to the fact that the E-field levels appearing at the high-resistance termination of the PT control circuit are low for the attenuating fields.

To understand the variation in frequency content of the induced voltages due to the transient fields, frequency spectra of these voltages have been calculated and are shown in Fig. 11. For the PT secondary circuit, the transient voltage frequency content is limited to $74.5 \mathrm{MHz}$, irrespective of the circuit configuration. This may be due to the fact that the capacitance of the LC loading becomes effective at approximately $40 \mathrm{MHz}$ for $1-\mathrm{m}$ length of the wiring and, hence, the induced voltage contribution decreases beyond this frequency. At the same time, for the CT control circuit, the transient voltage waveform is associated with high-frequency content due to inductive reactance of the LC loading. For both CT and PT control circuits, the change in frequency content of the transient voltages, with an increase in the length of the wiring, is found to be significant. This may be 


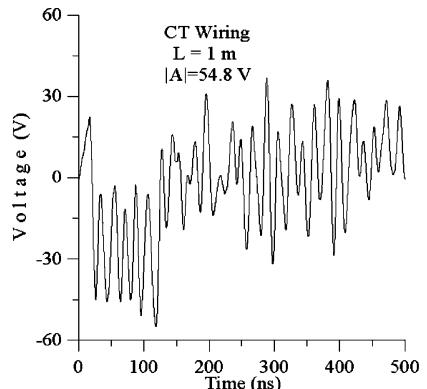

(a)

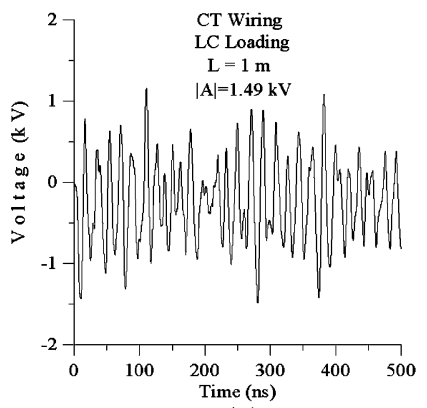

(c)

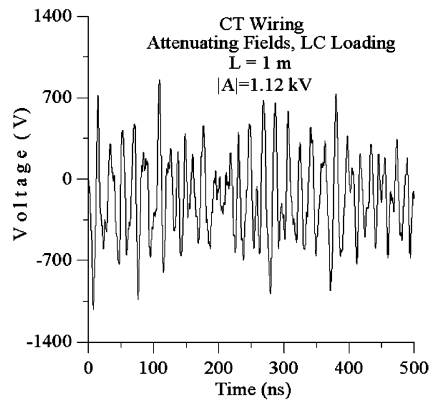

(e)

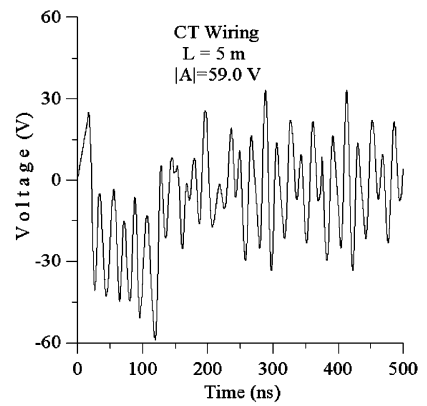

(g)

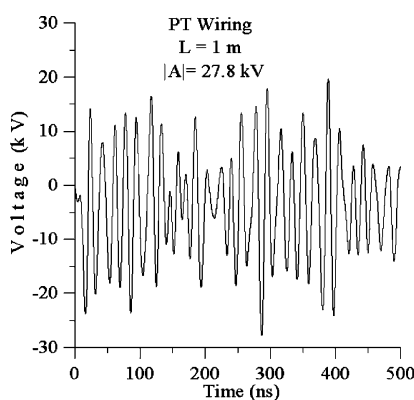

(b)

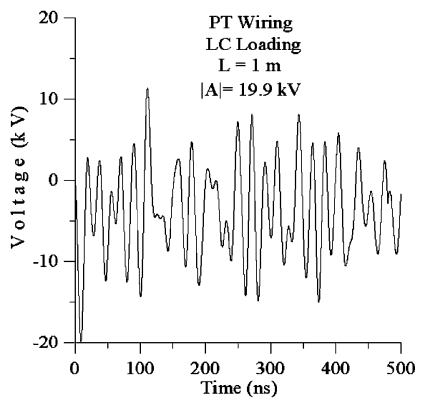

(d)

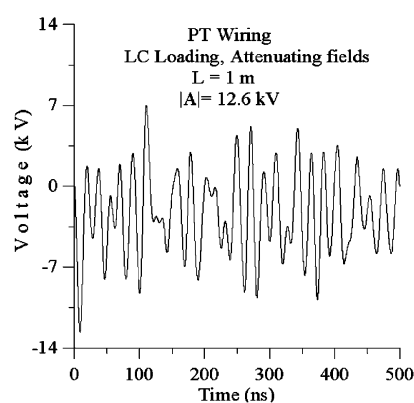

(f)

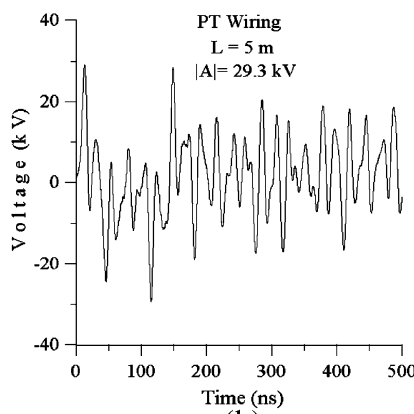

(h)

Fig. 10. Transient voltages at the terminals of the instrument transformers secondary circuit due to the field emission from the bus section.

due to the fact that there is a change in the resonant frequencies and, at the same time, a number of these frequencies increases with an increase in the length of the wiring. In order to understand the effect of transient field characteristics on the induced voltages, transients in the control circuitry have been calculated due to the field emission from the following GIS models [6], [7]:

Model-I: For a bushing model, at $(\mathrm{R}, \mathrm{H})=(2 \mathrm{~m}, 0.1 \mathrm{~m})$, radial and axial E-fields are 7.13 and $19.6 \mathrm{kV} / \mathrm{m}$, respectively;

Model-II: For a bushing model, at $(\mathrm{R}, \mathrm{H})=(2 \mathrm{~m}, 2 \mathrm{~m})$, radial and axial E-fields are 14.5 and $27.7 \mathrm{kV} / \mathrm{m}$, respectively;

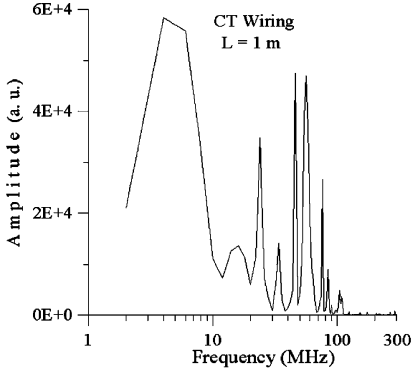

(a)

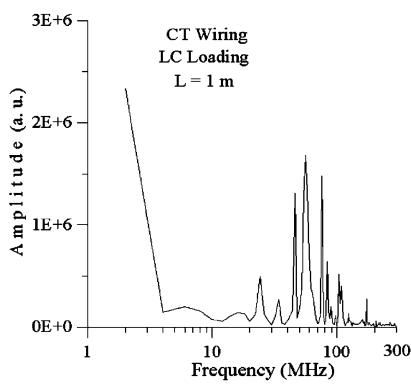

(c)

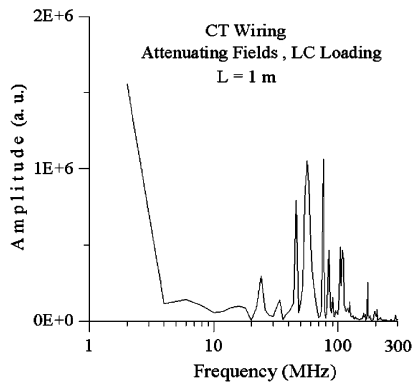

(e)

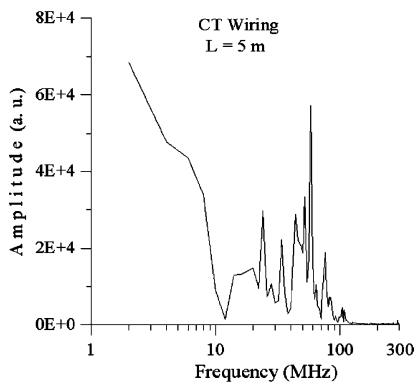

(g)

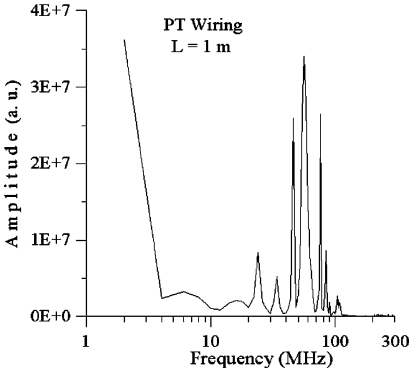

(b)

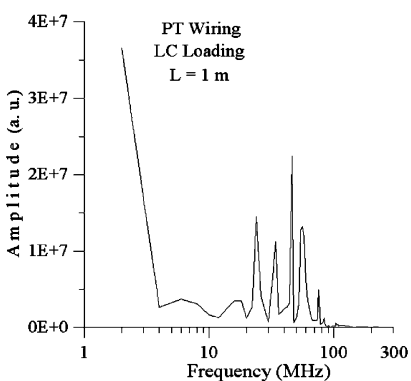

(d)

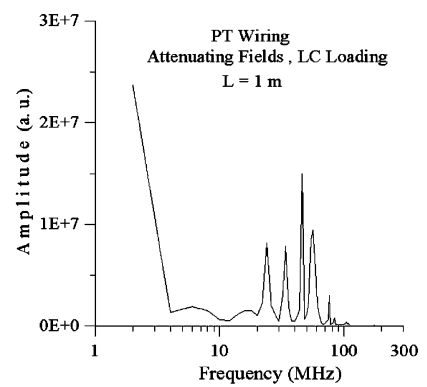

(f)

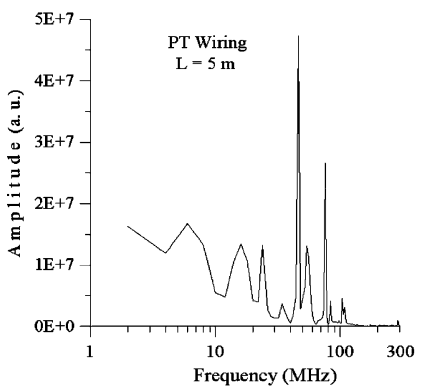

(h)
Fig. 11. Frequency spectra of the transient voltages at the load circuit of the instrument transformers control wiring.

Model-III: For a bus section model, at $(\mathrm{R}, \mathrm{H})=$ ( $3 \mathrm{~m}, 0.1 \mathrm{~m})$, axially at the middle of the bus section, radial and axial E-field levels are 5.47 and $24.14 \mathrm{kV} / \mathrm{m}$, respectively;

Model-IV: For a bus section model, at $(\mathrm{R}, \mathrm{H})=$ $(3 \mathrm{~m}, 0.1 \mathrm{~m})$, axially at $0.5 \mathrm{~m}$ from the middle of the bus section, radial and axial E-fields are 22.5 and 27.6 $\mathrm{kV} / \mathrm{m}$, respectively.

Table II shows the transient voltage levels for different configurations of the instrument transformers control circuitry. Based on the above study, the following features can be considered while designing control wiring/circuitry for a GIS. 
TABLE II

INDUCED VOLTAGES IN INSTRUMENT TRANSFORMERS CONTROL CIRCUITRY

\begin{tabular}{|c|c|c|c|c|}
\hline \multirow{2}{*}{ Configurations } & \multicolumn{4}{|c|}{ Induced Transient Voltages in $\mathrm{kV}$} \\
\cline { 2 - 5 } & I & II & III & IV \\
\hline CT wiring of 1m length & 0.444 & 0.578 & 0.055 & 0.296 \\
\hline $\begin{array}{c}\text { CT wiring of 1 m length with LC } \\
\text { loading }\end{array}$ & 1.31 & 1.80 & 1.49 & 2.00 \\
\hline $\begin{array}{c}\text { CT wiring of 1 m length with LC } \\
\text { loading and attenuating fields }\end{array}$ & 0.806 & 1.12 & 1.12 & 1.29 \\
\hline CT wiring of 5 m length & 0.606 & 0.747 & 0.059 & 0.298 \\
\hline $\begin{array}{c}\text { CT wiring of 5 m length with LC } \\
\text { loading }\end{array}$ & 1.395 & 2.15 & 2.23 & 2.69 \\
\hline $\begin{array}{c}\text { CT wiring of 5 m length with LC } \\
\text { loading and attemuating fields }\end{array}$ & 0.380 & 0.618 & 1.96 & 2.60 \\
\hline PT wiring of lm length & 21.1 & 29.0 & 27.8 & 32.8 \\
\hline $\begin{array}{c}\text { PT wiring of 1 m length with LC } \\
\text { loading }\end{array}$ & 20.9 & 30.0 & 19.9 & 31.0 \\
\hline $\begin{array}{c}\text { PT wiring of 1 m length with LC } \\
\text { loading and attemuating fields }\end{array}$ & 12.5 & 18.0 & 12.6 & 19.2 \\
\hline PT wiring of 5 mlength & 97.8 & 144.0 & 29.3 & 98.5 \\
\hline $\begin{array}{c}\text { PT wiring of 5 m length with LC } \\
\text { loading }\end{array}$ & 102.3 & 154.0 & 19.8 & 89.5 \\
\hline $\begin{array}{c}\text { PT wiring of 5 m length with LC } \\
\text { loading and attenuating fields }\end{array}$ & 25.1 & 39.0 & 7.57 & 25.7 \\
\hline
\end{tabular}

1) For the CT control circuit, the increase in a transient voltage level with an increase in the length of wiring, is only marginal.

2) Transient voltages in the PT secondary circuit increases with an increase of the length of the wiring.

3) The influence of the LC loading on the induced voltage levels depends on the characteristics of the transient field emission from the GIS modules and is more for the CT secondary circuit than for the PT secondary circuit.

4) The increase in inductance of the current transformer secondary winding may increase the induced voltage levels.

5) The transient field level tangential to the control wiring present in the GIS shall be maintained as low as possible, to limit the induced voltages in the control circuitry.

\section{CONCLUSION}

The induced transient currents/voltages in the control cable depend on the terminal impedance of the system, length of the control circuit, height of the cable above the ground plane, characteristics of the transient fields, and type of grounding of the cable sheath. There is a crossover frequency depending on the length and height of the cable above the ground plane, below which both-end grounding of the cable sheath gives higher transient voltages than one-end grounding of the cable sheath. The number of critical frequencies increases with an increase of the length of the control circuit. Transient voltages experienced by the control cable circuit are in the order of a few tens of volts to a few hundreds of volts depending on the characteristics of the cable (height, length and transfer impedance) and type of grounding of the cable sheath. The transient voltages appearing at the secondary circuit of the instrument transformers are in the order of a few kilovolts, characterized by the type of control circuit and are more for the potential transformers than for the CTs. The reduction in the induced voltage levels due to the attenuating transient fields is more for the PT secondary circuit than for the CT secondary circuit.

\section{ACKNOWLEDGMENT}

The authors would like to thank the Management of BHEL and the Indian Institute of Science for permission to publish this paper. The first author would like to thank Dr. H. S. Jain for his continuous encouragement and cooperation.

\section{REFERENCES}

[1] J. Meppelink, K. Diederich, K. Feser, and P. Pfaff, "Very fast transients in GIS," IEEE Trans. Power Del., vol. 4, no. 1, pp. 223-233, Jan. 1989.

[2] M. M. Rao, M. J. Thomas, and B. P. Singh, "Frequency characteristics of Very Fast Transient Currents (VFTC) in a 245 kV GIS," IEEE Trans. Power Del., vol. 20, no. 4, pp. 2450-2457, Oct. 2005.

[3] C. M. Wiggins, D. E. Thomas, F. S. Nickel, T. M. Salas, and S. E. Wright, "Transient electromagnetic interference in substations," IEEE Trans. Power Del., vol. 9, no. 4, pp. 1869-1883, Oct. 1994.

[4] D. E. Thomas, C. M. Wiggins, T. M. Salas, F. S. Nickel, and S. E. Wright, "Induced transients in substation cables: Measurements and models," IEEE Trans. Power Del., vol. 9, no. 4, pp. 1861-1868, Oct. 1994.

[5] C. M. Wiggins and S. E. Wright, "Switching transient fields in substations," IEEE Trans. Power Del., vol. 6, no. 2, pp. 591-600, Apr. 1991.

[6] M. M. Rao, M. J. Thomas, B. P. Singh, and P. Rajagopalan, Computation and measurement of electromagnetic interference generated during switching events in a GIS CIGRE. Paris, France, B3-202, 2004.

[7] M. M. Rao, M. J. Thomas, and B. P. Singh, "Electromagnetic (EM) field emission from the gas-to-air bushing in a GIS during switching events," IEEE Trans. Electromagn. Compat., accepted for publication.

[8] A. A. Smith, Jr., Coupling of External Electromagnetic Fields to Transmission Lines. New York: Wiley, 1987, Interference Control Technologies, Inc.

[9] S. M. Harvey, P. S. Wong, and P. M. Balma, "Radio interference and transient field from gas insulated substations," IEEE Trans. Power Del., vol. 10, no. 1, pp. 357-364, Jan. 1995.

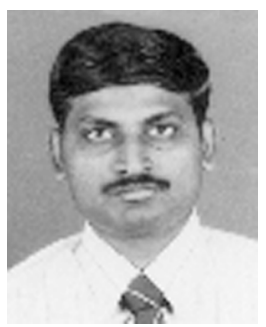

M. Mohana Rao was born in Guntur, India, in 1973. He received the B.Tech. degree from Sri Venkateswara University, Tirupathi, India, in 1994, and the M.Sc. Engg. and Ph.D. degrees from the High Voltage Department of the Electrical Engineering Division of the Indian Institute of Science, Bangalore, in 1996 and 2006, respectively.

Currently, he is Deputy Manager with Bharat Heavy Electricals Ltd., R\&D, Hyderabad, where he has been since 1996. His research interests are the design and development of gas-insulated substations (GIS), gas-insulated transmission lines, surge arresters, electromagnetic-interference (EMI)/electromagnetic-compatibility (EMC) studies in GIS, digital signal processing techniques in power systems, and a computational fluid dynamics (CFD)-based analysis of circuit-breaker arcs.

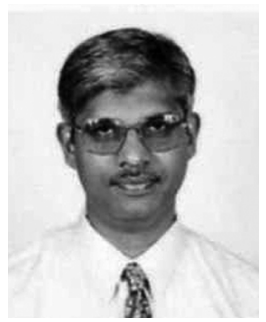

M. Joy Thomas was born in Kerala, India, in 1961. $\mathrm{He}$ received the B.Tech. degree in electrical engineering from the Institute of Technology, Banaras Hindu University, Varanasi, India, in 1983, and the M.Sc. Engg. and Ph.D. degrees from the Department of High Voltage Engineering, Indian Institute of Science, Bangalore, in 1986 and 1993, respectively.

Currently, he is an Assistant Professor with the Department of High Voltage Engineering, Indian Institute of Science. His interests are gas-insulated switchgear, electromagnetic interference (EMI)/electromagnetic compatbility (EMC), high-power electromagnetics, digital measurement of high voltages and currents, pulsed power engineering, extra high voltage (EHV) power transmission, electrical transients in power systems, condition monitoring of high-voltage power apparatus, nanodielectrics, and insulation engineering. 


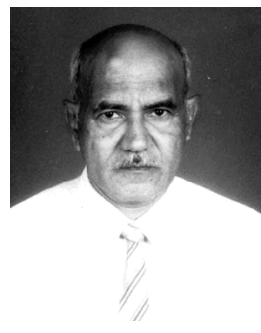

B. P. Singh was born in Bihar, India, in 1947. He received the B.E. degree in electrical engineering from Muzaffarpur Institute of Technology, Bihar, India, in 1968, the M.E. degree in high voltage engineering from the Indian Institute of Science, Bangalore, in 1971, and the Ph.D. degree from the Electrical Engineering Department, University of Liverpool, Liverpool, U.K., in 1974.

He was a Postdoctoral Fellow with the Electrical Engineering Department, University of Liverpool, Liverpool, U.K., for one year, working on a project sponsored by the United Kingdom Atomic Energy agency and thereafter for two years at the Reactor Research Centre, Kalpakkam, India. Currently, he is General Manager of High Voltage, Gas Insulated Switchgear and Advanced Technical Education, where he has been since 1978. His research areas are switchgear, high-voltage power transformers, motors, and capacitors.

Dr. Singh has been published in many research publications in various national and international journals and conferences. 